\title{
Urban-Rural Children Differences in Motor Coordination, Cardiorespiratory Fitness, and Agility
}

\author{
Riza Adriyani ${ }^{1, *}$ Dody Iskandar ${ }^{2}$, Lia Siti Camelia $^{3}$ \\ ${ }^{1,2,3}$ Unit of Public Sports Health (BKOM Bandung) \\ *Corresponding author. Email: adriyaniriza@gmail.com
}

\begin{abstract}
Rural children tend to be more active than urban children, which might affect both motor skills and physical fitness components. This study aimed to examine the effects of a living area on motor coordination, cardiorespiratory fitness levels, and Agility. We also investigated the relationship between motor coordination, cardiorespiratory fitness, and Agility in urban-rural children. School children aged 10 to 11 years participated in this study. Of these participants, 100 were urban children $($ Male $=47$, Female $=53)$, and the other 100 were rural children $($ Male $=48$, Female $=52)$. Gross motor coordination was measured by using Körperkoordinations Test für Kinder. A single test (1000 meters run) was used to measure cardiorespiratory fitness levels, while Agility was measured using a shuttle run test. Urban-rural differences were calculated by using an independent sample t-test. There were significant differences in motor coordination and cardiorespiratory fitness between urban and rural children $(\mathrm{p}<0.05)$, but there were no significant differences in their Agility. Urban children showed lower gross motor coordination $(74.15 \pm 10.67)$ than rural children $(81.03 \pm 8.62)$. Cardiorespiratory fitness of rural children $(7: 07 \pm 1.06)$ was better than urban children $(8: 13 \pm 1.57)$. Agility between urban $(12.78 \pm 1.38 \mathrm{~s})$ and rural $(12.80 \pm 1.11 \mathrm{~s})$ were almost similar. Statistical analysis showed a positive relationship between motor coordination, cardiorespiratory fitness, and Agility in both groups. Living areas affect motor coordination and cardiorespiratory fitness, but not Agility in children.
\end{abstract}

Keywords: Living areas, Gross motor coordination, Cardiorespiratory fitness, Agility

\section{INTRODUCTION}

Motor coordination is a predictor of physical activity levels in children. Good motor coordination will further affect the active lifestyle in adulthood. Motor coordination and Agility are fitness components directly related to daily activities and exercise. Several studies have shown that motor coordination and motor skills predict physical activity levels in children aged 6 to $10 \mathrm{y}$ [1]. Motor coordination also affects academic performance and cognitive function [2]. Children who have good motor coordination and agility skills will tend to have an active lifestyle as adults. Motor coordination will increase through activities during recess, as well as physical education at school [3].

Motor coordination is related to cardiorespiratory fitness, physical activity, and body composition [3]. The living areas could affect the physical fitness and kinesthetic developmental abilities of children aged 1112 years [4]. Several other studies have shown a correlation between cardiorespiratory fitness and living area, where rural children performed better than urban children [5]. Children who walk to and from school have better Agility and fitness skills of their lower extremities compared to children that use transportation facilities [6].

Motor coordination is affected by participating in structured sports (physical education in school), parental influence, and the environment $[7,8]$. Children who live in rural areas tend to be more active in their daily lives. The rural area provides more supports for the development of children's activities [9], while playground facilities in the urban area have been reduced and lead children to have a less active lifestyle.

The Körperkoordinations test Für Kinder (KTK) is a valid, reliable, simple, and low-cost gross motor coordination test that has been used widely in several countries [10]. Gross motor coordination research using Körperkoordinations Test für Kinder in children is still rare in Indonesia. Therefore, we would like to investigate significant differences in motor coordination, cardiorespiratory fitness, and agility capabilities between urban-rural children. We also try to find out the correlation between motor coordination, 
cardiorespiratory fitness, and Agility based on the living areas.

\section{MATERIAL AND METHODS}

\subsection{Participants}

We explained the aim and procedure of this research to the teachers and parents. Children who had feet or ankles injuries in the last six months, leg abnormalities, active in sports clubs and obese were not recruited in this study because it can affect the results of motor coordination measurements. Two hundred children (urban: $n=100$; rural: $n=100$ ) whose parents provided informed consent took part in this study. The mean age of urban children was $(10.42 \pm 0.50$ years $)$ while rural children were $(10.50 \pm 0.50$ years). The Research Ethics Committee, Ministry of Health-National Institute of Health Research and Development (19/07/2017) approved this study.

\subsection{Anthropometric Measurements}

\subsubsection{Body Mass Index}

Body mass index was determined by dividing the weight $(\mathrm{kg})$ by the square of height $(\mathrm{m})$ using the health scale. The standard weight status categories associated with body mass index are severely underweight, underweight, normal, overweight, and obese based on the national reference data for Indonesian children.

\subsubsection{Body Fat Percentage}

Skinfold measurements were taken from two sites (triceps and calf area) using Lafayette 01127A skinfold caliper. We apply the formula referenced in the Slaughter Lohman-Formula manual to calculate the body fat percentage. The result is an average of three trials.

\subsubsection{Gross Motor Coordination}

We used Körperkoordinations Test für Kinder (KTK) which consisted of four subtests. KTK test is valid to measure gross motor coordination components such as dynamic balance, rhythm, strength, laterality, speed, and Agility in children and adolescents, ranging from 5 to 14 years [11]:

1. Walking Backward (WB): walking backward three times along each of three balance beams $(3 \mathrm{~m}$ length; $6,4.5$, and $3 \mathrm{~cm}$ width). The maximum amounts of steps for each trial are 8 . A maximum of 24 degrees (eight per trial) was counted for each balance beam, which comprises a maximum of 72 steps for this test. The score was converted to the MQ result. Before the test, the subjects had one practice walk forward and backward on every balance beam.
2. Hopping Height $(\mathrm{HH})$ : jumping from one leg over an increasing pile of pillows $(40 \mathrm{~cm} \times 20 \mathrm{~cm} \times 5 \mathrm{~cm}$ each) after a short run-up. Every trial was evaluated, and the subject had three trials on every height. Three, two, or one point(s) were awarded for successful performance on the first, second, or third trial, respectively. A maximum of 39 points could be scored for each leg, yielding a possible maximum score of 78 and then converted to the MQ result.

3. Moving Sideways (MS): moving one plate sideways and the subjects stood on the other plate $(25 \mathrm{~cm}$ x $25 \mathrm{~cm} \times 5 \mathrm{~cm}$ ) in 20 seconds. The vessel had to be moved with two hands. The total points were counted and summed over two trials, then converted to the MQ result.

4. Jumping Sideways (JS): jumping bilaterally as many times as possible over a wooden rod $(60 \mathrm{~cm} \mathrm{x} 4 \mathrm{~cm}$ $\mathrm{x} 2 \mathrm{~cm}$ ) in 15 seconds. The number of jumps over two trials was summed and then converted to the MQ.

The motor quotient (MQ) was adjusted for age and gender. There are five categories: severe gross motor coordination disorder (MQ 56-70), moderate disorder (MQ 71-85), regular (MQ 86-115), good (MQ 116-130), and high gross motor coordination (MQ 131-145).

\subsubsection{Cardiorespiratory Fitness}

We used a single test method (1000 meters run) to assess cardiorespiratory fitness in children at the age of 10-12 years old. Results are time-traveled records.

\subsubsection{Agility}

The $30 \mathrm{ft}$ shuttle run used in this study to assess the agility capabilities in children. They run back and forth between two parallel lines as fast as possible, picking up tennis balls. We set up two lines of cones 30 feet apart and placed two tennis balls in the box. Starting at the line opposite the tennis balls box, the children run to the other line, pick up a tennis ball, return to the place it in a box behind the starting line, return to pick up the second tennis ball, and then run back across the line. Three trials were performed. Results are the quickest time trial is recorded.

\subsection{Statistical Analysis}

Testing normality of data using KolmogorovSmirnov test with $\mathrm{p}>0.05$. We used a parametric test or non-parametric test based on data distribution. Since the values of the subtests KTK - walking backward, jumping sideways, and moving sideways didn't have a normal distribution, the non-parametric test was used to analyze the data. The comparison of motor coordination and Agility between urban-rural was performed by independent sample t-test. At the same time, the 
cardiorespiratory fitness differences used the Mann Whitney U test, with a p-value less than 0.05 considered significant. We look at the gap between independent and dependent variables based on urban-rural strata. All ratio variables are transformed into ordinal, and stratification was analyzed by using the Mantel Haenzel method.

\section{RESULTS}

Table 1. Anthropometric Characteristic

\begin{tabular}{|l|c|c|}
\hline \multicolumn{1}{|c|}{ General Anthropometric } & Urban & Rural \\
\hline Age (mean \pm SD) years & $10.42 \pm 0.50$ & $10.50 \pm 0.50$ \\
\hline Height (mean \pm SD) cm & $134.52 \pm 6.03$ & $131.89 \pm 5.96$ \\
\hline Weight (mean \pm SD) kg & $30.49 \pm 5.56$ & $27.85 \pm 4.28$ \\
\hline $\begin{array}{l}\text { Body mass index } \\
\text { (mean } \pm \text { SD) } \mathrm{kg} / \mathrm{m}^{2}\end{array}$ & $17.05 \pm 1.97$ & $15.95 \pm 1.76$ \\
\hline $\begin{array}{l}\text { Percentage of body fat } \\
\text { (mean } \pm \text { SD) } \%\end{array}$ & $20.57 \pm 5.41$ & $17.51 \pm 4.64$ \\
\hline
\end{tabular}

Body mass index between urban-rural children was almost similar, but urban children tend to have more body fat than rural children (Table 1).

Table 2. Motor Coordination Differences between Urban and Rural Children

\begin{tabular}{|l|l|l|l|}
\hline Motor Coordination & \multicolumn{1}{|c|}{ Urban } & \multicolumn{1}{c|}{$\begin{array}{c}\boldsymbol{p} \text { - } \\
\text { value }\end{array}$} \\
\hline $\begin{array}{l}\text { MQ KTK } \\
\text { (mean } \pm \text { SD) points }\end{array}$ & $\begin{array}{l}74.15 \pm \\
10.67\end{array}$ & $81.03 \pm 8.62$ & $0.000^{*}$ \\
\hline $\begin{array}{l}\text { MQ Walking } \\
\text { backward (mean } \pm \text { SD) } \\
\text { points }\end{array}$ & $\begin{array}{l}105.45 \pm \\
8.68\end{array}$ & $\begin{array}{l}114.48 \pm \\
6.47\end{array}$ & $0.000^{*}$ \\
\hline $\begin{array}{l}\text { MQ Hopping height } \\
\text { (mean } \pm \text { SD) points }\end{array}$ & $\begin{array}{l}82.22 \pm \\
12.67\end{array}$ & $88.74 \pm 9.80$ & $0.000^{*}$ \\
\hline $\begin{array}{l}\text { MQ Jumping sideways } \\
\text { (mean } \pm \text { SD) points }\end{array}$ & $\begin{array}{l}17.77 \pm \\
\text { MQ Moving sideways } \\
\text { (mean } \pm \text { SD) points }\end{array}$ & $\begin{array}{l}92.15 \pm \\
13.56\end{array}$ & $0.000 *$ \\
\hline \multicolumn{2}{|l|}{$*$ Significantly different $p$-value < 0.05} \\
\hline
\end{tabular}

Based on motor coordination competence, there were significant differences in motor coordination performances between urban and rural children. It showed significant differences in walking backward, hopping height, and jumping sideways (Table 2).

Children with motor problems were found in urban children $(86 \%)$ and rural children $(64 \%)$, but rural children tend to have a better motor coordination competence than urban (Figure 1).

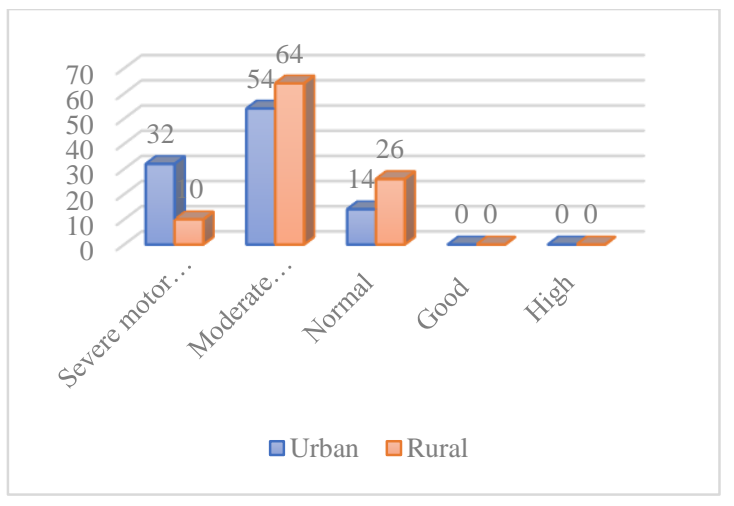

Figure 1 Distribution of motor quotients between urban-rural children

Table 3. Physical Fitness Differences between Urban and Rural Children

\begin{tabular}{|l|c|c|c|}
\hline \multicolumn{1}{|c|}{ Physical Fitness } & Urban & Rural & $\begin{array}{c}p- \\
\text { value }\end{array}$ \\
\hline $\begin{array}{l}\text { Cardiorespiratory } \\
\text { fitness } \\
\text { (mean } \pm \text { SD) (minutes, } \\
\text { seconds) }\end{array}$ & $8: 13 \pm 1.57$ & $7: 07 \pm 1.06$ & $0.000^{*}$ \\
\hline $\begin{array}{l}\text { Agility } \\
\text { (mean } \pm \text { SD) } \\
\text { (seconds) }\end{array}$ & $12.78 \pm 1.38$ & $12.80 \pm 1.11$ & 0.902 \\
\hline \multicolumn{2}{|l|}{$*$ Significantly different $p$-value < 0.05} & \\
\hline
\end{tabular}

Urban-rural children had significant differences in their cardiorespiratory fitness but not their agility capabilities (Table 3).

Table 4. Motor Coordination Relationship to Cardiorespiratory Fitness and Agility

\begin{tabular}{|c|c|c|c|c|c|}
\hline \multirow[t]{2}{*}{ Variable } & \multirow[t]{2}{*}{ Test } & \multicolumn{2}{|c|}{$\begin{array}{c}\text { Cardiorespiratory } \\
\text { fitness }\end{array}$} & \multicolumn{2}{|c|}{ Agility } \\
\hline & & Urban & Rural & Urban & Rural \\
\hline \multirow{2}{*}{$\begin{array}{l}\text { Motor } \\
\text { coordinatio } \\
\text { n }\end{array}$} & $\mathrm{r}$ & -0.374 & -0.329 & -0.651 & -0.551 \\
\hline & $\begin{array}{l}p \\
\text { value }\end{array}$ & $0.000 *$ & $0.001 *$ & $0.000 *$ & $0.000^{*}$ \\
\hline
\end{tabular}

Motor coordination relationship with cardiorespiratory fitness showed moderate strength in urban $(r=0.374)$ and rural children $(r=0.329)$ negatively. The relationship between motor coordination and Agility also showed a strong relationship $(\mathrm{r}=0.651)$ in urban children and a moderate relationship $(\mathrm{r}=0.551)$ in rural children with a negative direction. The negative relationship direction indicates that the higher the motor coordination, the faster they finished the cardiorespiratory fitness and shuttle run test, which means children had better fitness and agility capabilities. 
The correlation test also showed a positive relationship of motor coordination with cardiorespiratory fitness and Agility in urban-rural children (Table 4).

\section{DISCUSSION}

Unlike the other study [12], we found that the overall score of gross motor coordination was significantly different between urban and rural children. Participants obtained from the previous analysis came from various ethnicities and cultures that might not represent urban areas. The urban children in the previous study were not too affected by the culture of urbanization.

This present study showed lower motor coordination on walking backward, hopping height, and jumping sideways in urban children. This result is similar to the previous research where urban children showed more inadequate motor coordination on walking backward and jumping sideways [12].

The results of this study correspond to most of the researches that showed differences in cardiopulmonary fitness between urban-rural children [3,12-17]. Rural areas provide more outdoor space for unstructured activities and exercise for children. Active travel from and to schools (walking or biking) also affects greater physical activity levels in rural children than urban children.

Previous researches had inconsistent findings of agility capabilities in urban compared to rural children. Several studies found that rural children had better Agility than urban children $[13,18]$, but the others are not [19]. In our research, urban children had similar agility capabilities to rural children. Urban children had many opportunities to participate in structured sports (physical education inside schools and sports activities outside schools). Besides that, they were also supported by better facilities which will increase their agility skills. Specific exercises from structured sports will improve Agility.

The strong correlation between motor coordination and cardiopulmonary fitness tends to increase in childhood to adolescence. The results obtained in this study were similar to the results obtained by previous studies where there is a positive relationship between motor coordination and cardiopulmonary fitness. Good motor coordination means a better cardiorespiratory fitness level [7,8,14,20,21]. Cardiorespiratory fitness is a mediator between motor coordination and physical activity levels [22]. A good level of physical fitness will help children to participate in various physical activities more actively.

Children with low motor coordination might be associated with poor cardiorespiratory fitness and Agility [23]. A structured sports program that involves more complex skills is required to enhance children's motor coordination from ten [24]. Children's engagement in various physical activities and the limitation of passive activities are effective strategies to develop their motor coordination and prevent excess body weight.

Children with motor coordination problems tended to have physical inactivity in their later life. There is a need for early detection of motor coordination problems in children to improve their motor learning and participation in physical activities that lead to better physical fitness.

\section{CONCLUSION}

Rural children showed better motor coordination and cardiorespiratory fitness levels. Rural areas might support the development of children's motor coordination and cardiorespiratory fitness. A positive relationship was found between motor coordination, cardiorespiratory fitness, and Agility in urban-rural children.

\section{REFERENCES}

[1] V. P. Lopes, L. P. Rodrigues, J. A. Maia, and R. M. Malina, Motor Coordination as Predictor of Physical Activity in Childhood, Scand. J. Med. Sci. Sports, 2011, pp. 663-669.

[2] R. F. Valter, L. S. Michelle, and M. Thais, Motor Coordination Correlates with Academic Achievement and Cognitive Function in Children, Frontiers in Psychology, 2016, pp. 318.

[3] R. Chaves, A. B., Jones, T. Gomes, M. Souza, J. Maia, and S. Pereira, Effects of Individual and School-Level Characteristics on a Child's Gross Motor Coordination Development, Int. J. Environ. Res. Public Health, 2015, pp. 8883-8896.

[4] M. C. Gallotta, L. Guidetti, G. P. Emerenzian, E. Franciosi, and C. Baldari, Does Living Setting Influence Training Adaptations in Young Girls? Scand. J. Med. Sci. Sports, 2011, pp. 324-329.

[5] G. Kathleen, G. Urs, H. Martin, W. Ditmar, and M. Thomas, Effect of living area and sports club participation on physical fitness in children: A 4year longitudinal study, BMC Public Health, 2014, pp. 499.

[6] V. G. Emilio, R. R. Jonatan, and C. Palma, Associations between Active Commuting to School and Health-Related Physical Fitness in Spanish School-Aged Children: A Cross-Sectional Study, J. Environ. Res. Public Health, 2015, pp. 1036210373.

[7] L. E. Robinson, D. F. Stodden, L. M. Barnett, V. P. Lopes, S. W. Logan, L. P. Rodrigues, and E. D. Hondt, Motor Competence and Its Effect on Positive 
Developmental Trajectories of Health, Sports Med, Springer International Publishing Switzerland, 2015.

[8] S. K. Lai, S. A. Costigan, P. J. Morgan, et al., Do school-based interventions focusing on physical activity, fitness, or fundamental movement skill competency produce a sustained impact in these outcomes in children and adolescents? A systematic review of follow-up studies, Sports Med, 2014, pp. $67-79$.

[9] A. Cetin, S. Sevil, L. Karaoglu, and B. Yucekaya, Prevalence of Flatfoot among Elementary School Students, in Rural and Urban Areas and at Suburbs in Anatolia, Eur. J. Orthop. Surg. Traumatol, 2011, pp. 327-331.

[10] J. P. A. Moreira, M. C. Lopes, M. V. MirandaJúnior, N. C. Valentini, G. M. Lage, and M. R. Albuquerque, Körperkoordinations test Für Kinder (KTK) for Brazilian Children and Adolescents: Factor Analysis, Invariance and Factor Score, Front. Psychol, 2019, pp. 2524. DOI:.https://doi.org/10.3389/fpsyg.2019.02524.

[11] A. Scordella, S. Di Sano, T. Aureli, P. Cerratti, V. Verratti, G. Fanò-Illic, et al., The role of general dynamic coordination in the handwriting skills of children, Front. Psychol, 2015, pp. 580. DOI: https://doi.org/10.3389/fpsyg.2015.00580

[12] F. Walhain, V. G. Marloes, K. S. Lamur, H. E. J. Veeger, and A. Ladebt, Health-Related Fitness, Motor Coordination, Physical and Sedentary Activities of Urban and Rural Children in Suriname, Journal of Physical Activity \& Health, 2016, pp. 1035-1041.

[13] S. Bashir and I. A. Bhat, A Comparative Study of Physical Fitness Components among Rural and Urban Female Students of Kashmir, International Journal of Health, Sports and Physical Education, 2014, pp.19-23.

[14] A. M. Machado-Rodrigues, M. J. Coelho-E-Silva, J. Mota, C. Padez, R. A. Martins, S. P. Cumming, et al., Urban-rural contrasts in fitness, physical activity, and sedentary behavior in adolescents, Health Promotion International, 2012, pp. 118-127.

[15] T. C. Hian, Z. F. Mahmud, and T. Y. Choong, Physical Fitness Level between Urban and Rural Students-Case Study, Procedia- Social and Behavioral Sciences, 2013, pp.847-852.

[16] P. Chillon, F. B. Ortega, J. A. Ferrando, J. A. Casajus, Physical fitness in rural and urban children and adolescents from Spain, Journal of Science and Medicine in Sport, 2011, pp. 417-423.
[17] A. Karkera, N. Swaminathan, S. M. Pais, K. Visha, and B. S. Rai, Physical Fitness and Activity Level among Urban School Children and Their Rural Counterparts, Indian J. Pediatr, 2014, pp. 356-361.

[18] P. Das and P. Chatterjee, Urban-Rural Contrasts in Motor Fitness Components of Youngster Footballers in West Bengal, India, Journal of Human Sport \& Exercise, 2013, pp. 797-805.

[19] D. Novak, E. R. Bernstein, H. Podnar, and Y. Vozzolo, Differences in The Fitness Levels of Urban and Rural Middle School Students in Croatia, Physical Educator, EarlyWinter, 2015, pp. 553-576.

[20] Gu Xiangli, K. T. Thomas, and Y. L. Chen, The Role of Perceived and Actual Motor Competency on Children's Physical Activity and Cardiorespiratory Fitness During Middle Childhood, Journal of Teaching in Physical Education, 2016, pp. 388-397.

[21] E. M. Post, Associations among Perceived Motor Competence, Motor Competence, Physical Activity, and Health-Related Physical Fitness of Children Ages 10-15 Years Old, Master's Thesis, University of Tennessee, 2016, pp. 1-87.

[22] Z. Khodaverdi, A. Bahram, D. Stodden, and A. Kazemnejad, The Relationship between Actual Motor Competence and Physical Activity in Children: Mediating Roles of Perceived Motor Competence and Health-Related Physical Fitness, Journal of Sport Sciences, 2016, pp. 1523-1529.

[23] M. T. Kantomaa, J. Purtsi, A. M. Taanila, J. Remes, H. Viholainen, et al., Suspected Motor Problems and Low Preference for Active Play in Childhood are Associated with Physical Inactivity and Low Fitness in Adolescence, PLoS ONE, 2011, e14554.

[24] S. S. Geertsen, R. Thomas, M. N. Larsen, J. N. Andersen, M. K. Jensen, V. Korup, C. M. Nielsen, J. Wienecke, C. Ritz, P. Krustrup, J. Lundbyejensen, and I. M. Dahn, Motor Skills and Exercise Capacity are Associated with Objective Measures of Cognitive Functions and Academic Performance in Preadolescent Children, Plos ONE, 2016, pp.1-16. 